\title{
Potential Barriers to Implementing Energy Management System in Pakistan: A Case of Wet Processing in the Textile Sector
}

\author{
Muhammad Junaid $^{1 *} \quad$ Dr. Muhammad Aasim ${ }^{2} \quad$ Dr. Salman Manzoor ${ }^{3}$ \\ 1.Student at Karachi University Business School (Seat\#P16302036), University of Karachi P.O. Box No 75270, \\ Karachi, Pakistan \\ 2.Chairman of Karachi University Business School \& Research Supervisor, University of Karachi P.O. Box No \\ 75270, Karachi, Pakistan \\ 3.Assistant Research Supervisor Karachi University Business School, University of Karachi P.O. Box No 75270, \\ Karachi, Pakistan
}

\begin{abstract}
The purpose of the research was to observe that greater and more structured barriers that limit the implementation of energy management systems. This was, however, narrowed to focus especially on the wet processing in the textile sector of Pakistan. It was considered pivotal to focus on the economic and regulatory barriers as operational barriers had been observed the case for previous researches. To ensure these mixed research methods were used to cross over into both qualitative and quantitative research method. Data collection remained limited due to time constraints, and five managers have opted for the interviews, while 130 respondents formed the sample for the questionnaire survey. Finding has led to the conclusion that a major economic barrier was the increase in tariff for the commercial sector, which makes energy cost rise higher and leave lesser room to explore new options such as the EMS. It has also been found that regulations are lenient, and apparently, no policy exists to limit energy usage. Keywords: Wet-processing, Energy Management System, Textile Sector, Energy efficiency.

DOI: $10.7176 / \mathrm{JETP} / 10-1-04$
\end{abstract}

Publication date: January $31^{\text {st }} 2020$

\section{Introduction}

In the current era, the changes in the industry practices are observed, and management of firms are likely to perform operations with sustainability Energy management system is one of the solutions that allow management to overcome shortage issues as it reduces the consumption by allocating the energy in a most appropriate manner. According to the study of Johansson (2015), the need of energy is increasing rapidly due to which proper management system is required as authorities are working to fulfill the need of energy in each sector. The energy management system increases the capacity of production, and it maximizes the overall performance.

Climatic changes and energy demand are two major problems that are considered by experts at a global scale. Both factors cannot be completely controlled by anyone, but, some initiatives can turn climatic changes and need for energy in favor. Pakistan is one of the developing countries, and the government is working for the further development and growth. The energy demand in-country is increasing rapidly due to which main bodies of electricity are working together. The bodies that are dealing with energy include Pakistan Atomic Energy Commission (PAEC), KESC (Karachi Electricity Supply Company) and WAPDA (Water and Power Development Authority). To understand the demand for energy as per sector management divided demand as per the requirement of the sector such as commercial, transport, industrial, domestic and agricultural. However, due to the change in demand in the past few years, problems of shortage are faced by each sector (Nadeem, 2014).

Further, Nadeem (2014), the industrial sector practices in Pakistan are increasing, and the government does not have any plan as they do not know how they will fulfill the demand for energy. The lack of regulations, planning and policies become the barrier for the industrial sector. The performance standards are also missing of the wet processing due to which issues are raised. Shaikh (2009), wet processing enhances the overall operations of the textile industry. However, it has been observed that multiple channels are used in wet processing. In wet processing, the chemical is used to reduce reaction of chemicals management is likely to use the energy as it reduces multiple activators. The current capacity of energy production cannot fulfill the demand due to which shortage issues are raised. In the light of Dawn Report (2012), it has been observed that global crises in the energy sector are increased, and Pakistan is also witnessing the electricity shortage issues. There is a lack of management and no proper policies, which is further increasing the issues for management. However, the problem can be overcome by management with the help of proper energy management system.

\subsection{Research Aim and Objectives}

The research aims to analyses the barriers rising in the utilization of energy management in the wet processing carried out within the Textile sector of Pakistan.

Following research objectives have been phased out to be studied during the course of the study:

- To understand the concept of the Energy Management System. 
- To analyse the benefits of using Energy Management System in the Industrial Sector of Pakistan.

- To determine potential barriers of using Energy Management System for Wet Processing in Textile Sector of Pakistan.

- $\quad$ To provide recommendations for neutralising the barriers to implementing Energy Management System for Wet Processing in Textile Sector of Pakistan.

\subsubsection{Research Question}

Drawn from the research objectives above, the following research questions have been answered within the study ahead:

- What is the role of Energy Management Systems in controlling energy consumption?

- What benefits can the textile sector of Pakistan gain from using Energy management Systems within its operations?

- What are the possible positive impacts of energy management systems in wet processing within the textile sector of the country?

- What are the barriers faced when adopting the use of the Energy Management Systems within the Textile sector of Pakistan?

- What may essential measures be considered to reduce the barriers faced during the acceptance of Energy Management Systems in Pakistan for wet processing in Textile Industry?

\subsubsection{Hypothesis}

H1: There is an impact of economic barriers on the deployment of Energy Management System in Textile sector of Pakistan

H0: There is an impact of economic barriers on the deployment of Energy Management System in Textile sector of Pakistan

$\mathrm{H} 2$ : There is an impact of regulatory barriers on the deployment of Energy Management System in Textile sector of Pakistan

H0: There is no impact of regulatory barriers on the deployment of Energy Management System in Textile sector of Pakistan

H3: There is an impact of Energy Management System in for efficient wet processing Textile sector of Pakistan

H0: There is no impact of Energy Management System in for efficient wet processing Textile sector of Pakistan.

\subsection{Research Gap}

The literature gap has been observed in the past few studies due to which the current study is conducted by the researcher. The gap has been analyzed from the study of Muhammad Tahir Hassan, Stas Burek \& Muhammad Asif published in the year 2016. The selected article is mainly based on SMEs and energy efficiency in small firms. However, the article further focuses on the energy efficiency in the operation of the industry, but, there was a lack of information related to the energy management system of the country. The current research, fulfill the gap by focusing on the energy management system in wet processing and major focus is on the textile sector of Pakistan. The article highlight problems and issues that are faced by the managers of the industry while implementing an energy management system. Further, barriers related to the economy and regulatory are also highlighted that is faced by experts in managing wet processing with the help of an energy management system.

\subsection{Conceptual Framework}

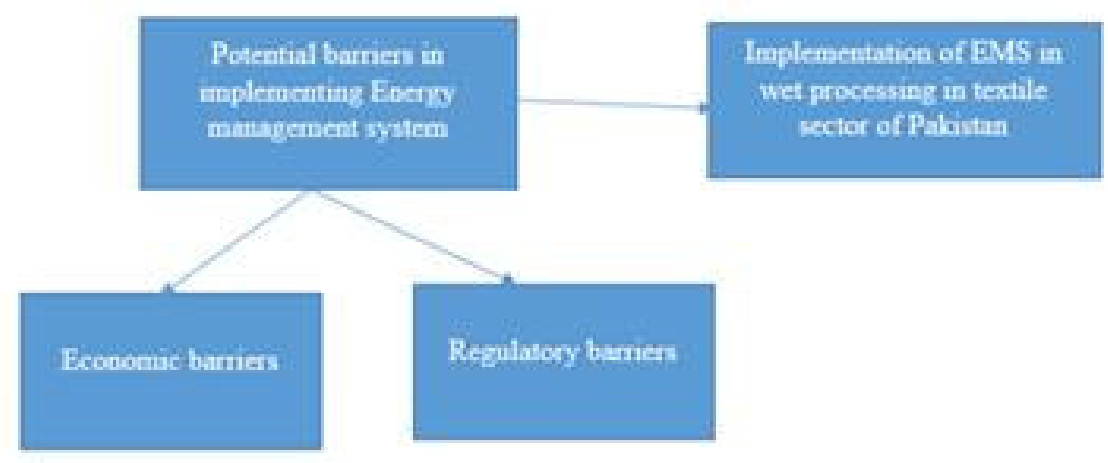

The above mention conceptual framework is designed by the researcher to complete the study effectively and to create a better understanding related to the dependent and independent variable of the study. 


\section{Literature Review}

\subsection{Concept of Energy Efficiency}

The concept of energy efficiency is considered as it provides multiple benefits. As per the study of Mori et al. (2011), energy efficiency reduces the consumption of energy in the complete process of operations as resources are allocated in the most appropriate manner. It is concluded that energy efficiency is one of the ways to reduce the cost of operations. In the view of Bunse et al. (2011), energy consumption allows the management to complete the process of operation in minimum cost and energy. Furthermore, energy efficiency allows the management to perform operations as per set goals and achieve desired results in low cost. In other words, energy efficiency is higher productivity in low energy consumption.

\subsection{Industrial usage of Energy Management System}

As per the study of Bunse et al. (2011)), to ensure that energy consumption is optimal in an organization, the management needs to work on the entire energy management system. The researcher further added, in the industrial sector, the energy management system is used in the multiple operations due to which there are wastage issues. It has been concluded that there is no proper system to maintain the usage of energy due to which issues of energy loss occurs. The need for energy management is consistently similar to the need for energy efficiency. It is added by the researcher, and it is concluded that effective planning for the usage of energy is considered for an industrial sector of the country. According to the Hepbasli \& Ozalp (2003), in the light of the Turkish industrial sector, the implementation of an energy management system enhances the overall results as well as the potential of the industry sector. Cost related issues are quite common in the industrial sector, and management work on it to overcome the problem as consumption of energy require a significant amount of money. However, techniques and technology of the energy management system might be complex, but, it can reduce the cost of operations and provide benefit for the long-run. The expertise is required in the industrial sector to manage operations with the energy management system. However, transformation is considered because of the benefits as well as improvement in operations.

\subsection{Energy Consumption by the Textile Sector of Pakistan}

The textile sector in Pakistan plays a significant role in the development of the economy and contributes to the exports of the country. There is a significant demand for energy from the textile industry as they are managing operations at a larger scale. As per the report, it has been highlighted that the textile sector also consume gas as energy and around 50\% of energy is required by the industrial sector of Pakistan. The technological development in the textile sector is observed due to which alternatives are being considered. To fulfill the responsibilities of the energy industry, the energy is generated through diverse portfolios which include coal, oil and gas. The textile sector of Pakistan is the largest consumer of electricity in Pakistan. In the below pie, diversified energy portfolio has been discussed for the textile sector of the country:

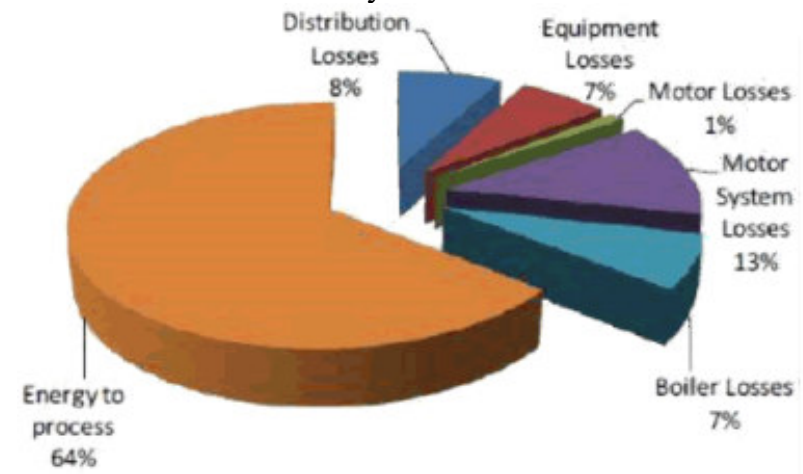

As per the study of Khude (2017), in the textile sector, the energy management system has been considered to reduce the losses of energy. In the light of Pakistan textile sector, it has been observed that experts of the industry are likely to used advanced technology and they are using spinners and looms which is part of production operation and require the energy which increases the energy loss. Further, it is added by Khan and Khan (2010), the energy portfolio in Pakistan is quite diverse. The textile sector of Pakistan is using both fuel and electricity energies. Amongst all challenges, the initial level problem which is faced by textile industry experts is related to energy consumption. However, by focusing on the textile sector as a whole, it might be quite energy-efficient. But, various areas are increasing the consumption of energy such as around $15 \%$ of energy is consumed by a wet processing system. It has been observed that in Pakistan, there is a problem of lack of energy due to which textile sector faced the major issues in the past. Moreover, until today there is no effective solution that has been derived as excessive consumption of electricity and fuel is increasing the cost of operation significantly. The same level of productivity 
can be achieved at low cost if management work on the energy management system as it enhance and improve the operations.

\subsection{Energy Management System and its Implementation in Pakistan Industrial Sector}

The energy management system is playing a significant role in the industrial sector as it reduces the cost of operations and increases productivity. It became the requirement of the industry sector because of the continuous development at the global scale. Also, new technological changes require more energy to perform operations effectively. In Pakistan, authorities are focus on the energy management system, and the major focus is on foundries. As per the report Pakistan Foundry Association (2019), the implementation of an energy management system has been observed within foundries. Foundries are the industries or sector which consumes the highest energy in Pakistan. The industries in Pakistan are consuming almost half of the energy. However, the sources are still limited, and management requires electricity at a larger scale. As per the United Nation Industrial Development Organization (2019), highlighted that the energy management system is a solution as it reduces the cost and increases the productivity of the entire industrial sector of Pakistan. The technical view of the industry sector management of Pakistan is shown in the portrait below:

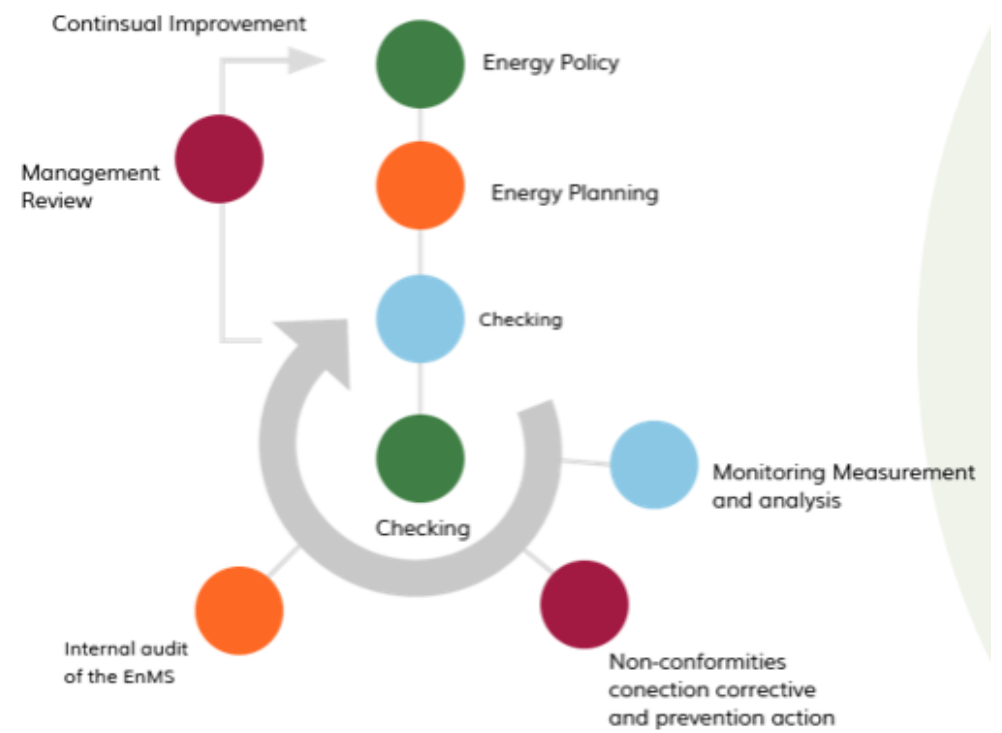

The above mention program helps the United Nation Industrial Development Organization in the growth as it is part of the ISO 5001. The program makes sure that in an industrial sector energy management is implemented effectively. It is added by the Daily Times (2019), to enhance the awareness and productivity management is likely to promote and develop a plan for energy management system in Pakistan.

\subsection{Benefits of Energy Management in Wet Processing}

The textile industry is playing a significant role in the economy of the world and requires a huge amount of energy to perform operations of business effectively. As per the study of Alkaya \& Demirer (2014), the energy management system is quite beneficial for the growth of the industry. It has been observed while performing operation management makes sure that energy is sufficient as it is essential to perform textile industry operations. When management uses wet processing, they can reduce electricity and perform operations by consuming the water as it reduces energy consumption as a whole in the textile industry. In the view of May et al. (2017), the claim is further supported by the researcher related to the usage of the energy management system. The researcher further added that while performing an operation with wet processing along with energy management system increase the sustainability in a complete sector. The wet processing require the significant amount of the energy in both forms electricity and heat. In regard to this, the researchers added that to ensure sustainability and development managers need an efficient energy management system.

However, in the view of Diabat et al. (2014), the energy management system allows experts of the industry to perform the operation in a structured form as well as it enhances the operation of wet processing and it also impacts on the supply chain of the textile industry positively. The implement of the energy management system during wet processing have benefits as it reduce the consumption of electricity which increase the profitability of an organization. The energy management is promoted by the expert because it secures energy and increases the profitability of overall sectors, as well as management, can get more output in limited input. According to the Uddin (2014), to fulfil the need of the textile sector, the management requires effective energy system for the machines, especially in the finishing process that is known as wet processing. The machine consumes electricity 
for the purpose of the dye. Furthermore, the energy management system also reduces the consumption of heat energy and enhances the overall monitoring system of the textile industry.

\subsection{Barriers to Energy Management System Implementation Textile Sector of Pakistan}

It has been observed that problem related to the implementation of an energy management system is raised on a global scale. However, it is added by the researcher that most of the countries are likely to implement energy management system by increasing auditing activities to overcome shortage problem and enhance the performance of entire organization activities (Thollander \& Palm, 2012). The one barrier which is highlighted by Backlund et al. (2012), there is a gap in the textile industry due to which they are not able to implement the energy management system effectively. The firm has no specific skill set which allows them to implement the energy management system due to which it becomes a barrier. As per the study of Mirjat et al. (2017), Pakistan textile industries are not able to implement the energy management system due to which issues are raised. Due to barriers energy authorities are also facing issue to fulfill the demand of the textile sector as they are not using electricity in an appropriate manner. It has been observed that the industry of Pakistan is in growing face and management is facing more challenges due to energy deficiency. Brunke et al. (2014), the complete structure require to impalement energy management system. But, lack of regulation and policies also become the barriers to implementation of an energy management system in the textile sector of Pakistan.

\section{Methodology}

The methodology of the study is considered by researchers as it is a step by step approach which contributes to completing the study effectively. The approaches of study are considered by the researchers to gain knowledge as per the nature of the study (Silverman, 2016). The common approaches that are used most commonly are inductive and deductive. In the current study, the researcher has been used deductive approach as data is collected on the existing topic and the researcher designed hypothesis at the start of the study. The researcher is likely to present a relationship among dependent and independent variables with the help of a deductive approach as information is gathered from the survey as well. However, to complete the study effectively, the selected researcher design is explanatory. The purpose of selecting explanatory research design is it allows the researcher to present information related to potential barriers to implementing an energy management system in Pakistan: a case of wet processing in the Textile Sector in detail. Furthermore, information has been gathered from the secondary sources as well as expert opinion is taken, which allow the researcher to present detail information related to variables.

According to the Stacks\&Salwen (2014), the research philosophy is essential to complete the study and derive findings appropriately. Three main philosophies which is considered by researchers is interpretive, positivism and realism. Realism philosophy is considered by researchers when they work on real-life events. However, to complete the study, the researcher has been adopted positivism philosophy because in this numerical information is required, which is derived by the researcher from the primary source. Positivism philosophy allows the researcher to present logical information. The researcher used both qualitative and quantitative technique to complete the study. The quantitative approach has been used as it allows the researcher to derive a large number of data easily. The researcher used a survey tool for a quantitative approach to gathering information for the current study. The qualitative approach of the study is considered by the researcher as it helps to gather detailed information and fulfill the requirement of variables.

The information has been gathered from both sources primary and secondary sources to fulfill the requirement of the study effectively. The researcher used secondary source to gain information regarding the topic of the study as a prior study helps the researcher to understand the topic more appropriately. The primary source has been considered by the researcher to gather more specific information related to the topic and fulfill the requirement of objectives. Moreover, the sampling technique for the survey is around 130 and respondents are employees. The interview sample size is five and information have been gathered from managers. The two common techniques for sampling is probability and non-probability. According to Alvesson \&Sköldberg (2017), sampling techniques are considered by researchers to gain information from appropriate respondents. For the current study, the researcher gain information by using non-probability sampling technique and further convenience tool is used for the questionnaire. However, for an interview activity, the researcher has been selected as a snowball sampling technique.

\section{Discussion and Findings}

4.1 Statistical Analysis

The data of the study has been analyzed with the help of SPSS as it enhances the credibility of the data. 


\section{Reliability test}

Case Processing Summary

\begin{tabular}{|c|c|c|c|}
\hline & & $\mathrm{N}$ & $\gamma$ \\
\hline \multirow[t]{3}{*}{ Cases } & Valid & 130 & 87.2 \\
\hline & Excludeda & 19 & 12.8 \\
\hline & Total & 149 & 100.0 \\
\hline
\end{tabular}
variables in the procedure.

\section{Reliability Statistics}

\begin{tabular}{|r|r|}
\hline $\begin{array}{c}\text { Cronbach's } \\
\text { Alpha }\end{array}$ & Nof ltems \\
\hline .873 & 10 \\
\hline
\end{tabular}

The reliability of the data is considered because if data of the study is not reliable, the researcher needs to gather complete data again. Cronbach's alpha should be 0.50 before moving towards the further of the study. It has been analyzed the Cronbach's alpha of the current study is 0.873 , which indicates that gathered data is highly credible.

\section{Regression analysis}

\begin{tabular}{|c|c|c|c|c|}
\hline \multicolumn{5}{|c|}{ Model Summary } \\
\hline Wodel & $\mathrm{F}$ & R Bquare & $\begin{array}{c}\text { Adjusted R } \\
\text { Gquare }\end{array}$ & $\begin{array}{l}\text { Std. Error of } \\
\text { the Estimate }\end{array}$ \\
\hline 1 & $.945^{a}$ & .893 & .992 & .27928 \\
\hline
\end{tabular}

a. Predictors: (Constant), RB, EB

It has been derived with the help of the regression table that there is a strong relationship among dependent and independent variable as the derived value of $\mathrm{R}$ square is .945 .

\section{Anova}

\begin{tabular}{|c|c|c|c|c|c|c|}
\hline \multicolumn{7}{|c|}{ ANOWA } \\
\hline & & $\begin{array}{l}\text { Sum of } \\
\text { SuLares }\end{array}$ & $d f$ & Mean Square & $\mathrm{F}$ & Big. \\
\hline \multirow[t]{3}{*}{1} & Regression & 66.661 & 1 & 66.661 & 237.226 & $.000^{3}$ \\
\hline & Residual & 35.968 & 128 & .281 & & \\
\hline & Total & 102.629 & 129 & & & \\
\hline
\end{tabular}

a. Predictors: (Constant), FB

b. Dependent Variable: EM

The ANOVAANOVA highlights the significance of the data. In the current study, the derived value is .000 , which indicates that data is highly significant as it less than the threshold value, which is 0.05 .

\section{Coefficient}

Coefficients $^{\Xi}$

\begin{tabular}{|c|c|c|c|c|c|c|}
\hline \multirow{2}{*}{\multicolumn{2}{|c|}{ Wadel }} & \multicolumn{2}{|c|}{ Unstandardized Coefficients } & \multirow{2}{*}{$\begin{array}{c}\text { Standardized } \\
\text { Coefficients } \\
\text { Beta }\end{array}$} & \multirow[b]{2}{*}{$\mathrm{t}$} & \multirow[b]{2}{*}{ Biq. } \\
\hline & & $\mathrm{B}$ & Btd. Error & & & \\
\hline \multirow[t]{3}{*}{1} & (Constant) & -.081 & .080 & & -1.008 & .315 \\
\hline & EB & .934 & .038 & 913 & 24.849 & .000 \\
\hline & $\mathrm{FE}$ & .068 & .049 & .051 & 1.384 & 169 \\
\hline
\end{tabular}

a. Dependent Variable: Eli

The coefficient allows the researcher to gain information, either variables of the study are significant or not. It has been derived that sig value is 0.00 for the economic barrier, which shows that there is a strong impact on the economic variable on the implementation of an energy management system. However, the regulatory barrier value is 0.169 , which also show that there is an impact of a regulatory barrier on the implementation of EMS. 


\section{Correlation}

\section{Correlations}

\begin{tabular}{|c|c|c|c|c|}
\hline & & Ely & EB & $\mathrm{RB}$ \\
\hline \multirow[t]{3}{*}{ EMI } & Pearson Correlation & 1 & $.944^{x x}$ & $.612^{x x}$ \\
\hline & Sig. (2-tailed) & & 000 & .000 \\
\hline & N & 130 & 130 & 130 \\
\hline \multirow[t]{3}{*}{$\mathrm{EB}$} & Pearson Correlation & $.944^{\mathrm{xx}}$ & 1 & $.615^{\mathrm{xx}}$ \\
\hline & Sig. (2-tailed) & .000 & & .000 \\
\hline & $\mathrm{N}$ & 130 & 130 & 130 \\
\hline \multirow[t]{3}{*}{$\mathrm{RB}$} & Pearson Correlation & $.612^{\mathrm{mm}}$ & $.615^{\mathrm{nn}}$ & 1 \\
\hline & Sig. (2-tailed) & .000 & .000 & \\
\hline & N & 130 & 130 & 130 \\
\hline
\end{tabular}

*. Correlation is significant at the 0.01 level (2-tailed).

Through the above correlations, it has been found that there is a strong correlation among variables because the Pearson correlation of each variable is higher than 0.40 .

\subsection{Demographics}

The demographic information from the primary source is gathered while conducting the survey. However, demographic information has been mentioned in the table below:

\section{Year of experience}

\begin{tabular}{ll}
\hline Years & Percentage \\
\hline Less than one year & $23.8 \%$ \\
1-3 years & $39.2 \%$ \\
3-5 years & $23.3 \%$ \\
More than five years & $14.6 \%$ \\
\hline
\end{tabular}

\section{Departments}

\begin{tabular}{|l|l|}
\hline Finance department & $\mathbf{4 1 . 5 \%}$ \\
\hline Production department & $21.5 \%$ \\
\hline Engineering department & $17.7 \%$ \\
\hline Operational Department & $19.2 \%$ \\
\hline
\end{tabular}

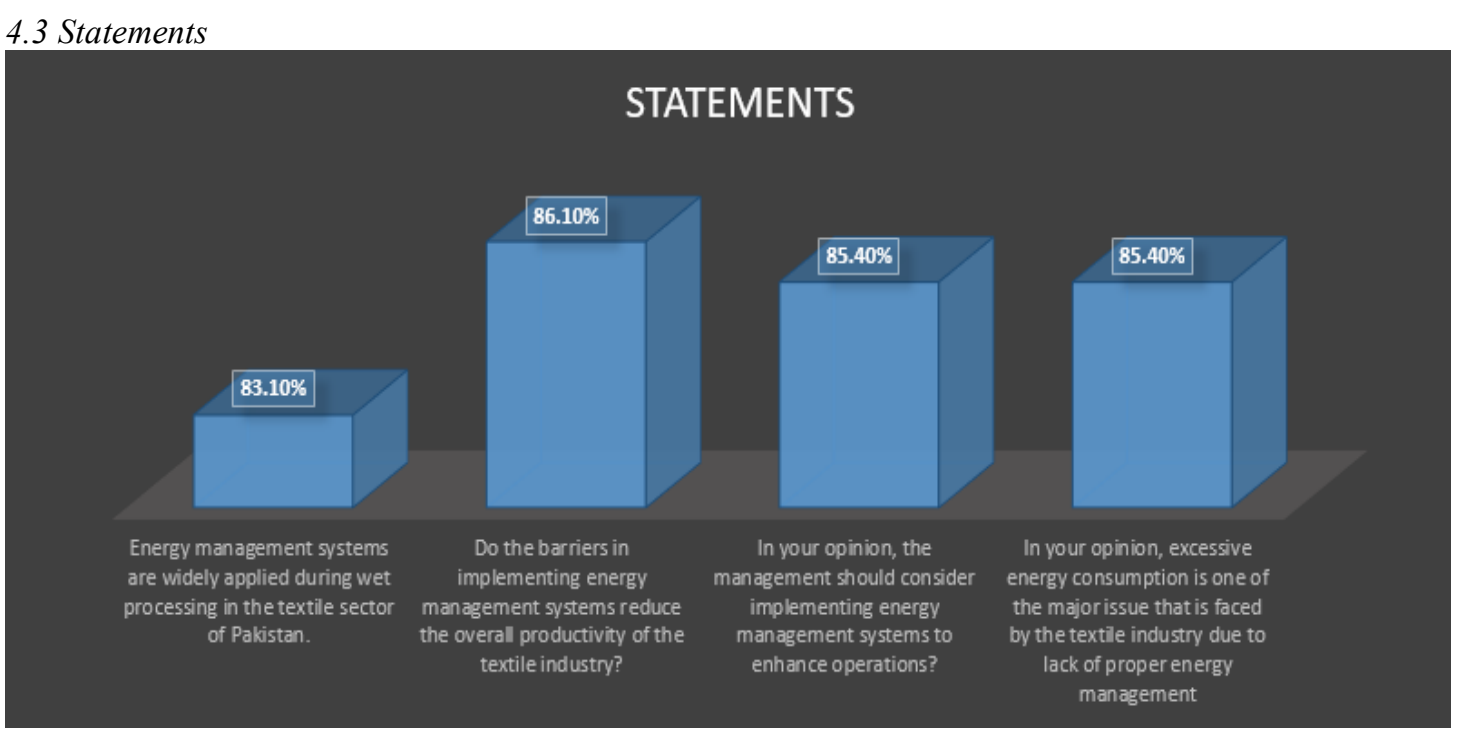

The textile sector witnesses a serious concern with energy management. It can be observed that to the question related to the energy management system in wet processing in textile sector of Pakistan, the reopens remain in affirmation even though the EMS is not concisely observed through it. This provides effective observation of the fact that awareness remains low for the energy sector in relation to EMS and its benefits. Barriers have been considered to rise as energy management systems are sought after. Where nearly $86.10 \%$ of the respondents believe 
that the sector witnesses a serious decrease in productivity as a result of such EMS related barriers, responses to the statements that dwelt over the fact should EMS be implemented during the wet processing in the textile sector of Pakistan were majorly in affirmation where the rate of agreement was nearly $85.40 \%$. The same rate was seen when asked whether or not the textile industry observes witnesses higher amounts of energy usage due to the inability of implementing the EMS.

If we are to observe interview responses from Manager E:

"I find energy efficiency amongst the key factors that could help us in the textile industry to have a better chance of success. We are amongst the largest industrial energy consumers, and if that is controlled with limited energy usage to have the same or even higher production, we can boast larger profits."

This has been the case for all the managers when asked for should the EMS be made functional across the textile industry, especially in wet processing. The literature brought about similar findings and lesser contradiction was observed.

In light of literature, it has been observed that challenges are faced by firms related to energy shortage due to the increase in the demand of the industry. It has been observed that the manufacturing industry is growing in Pakistan and technology development is promoted in the industry due to which issues of electricity is raised (Khude, 2017). As per the study of Khan \& Khan (2010), the energy is produced from a different source but, still, needs are not fulfilled yet. It has been derived that firms are facing multiple barriers while implementing an energy management system among with wet processing. It has been considered by the firm because the energy management system reduces the cost of operations and allows management to use energy in the most appropriate way.

\subsection{Economic Barriers}

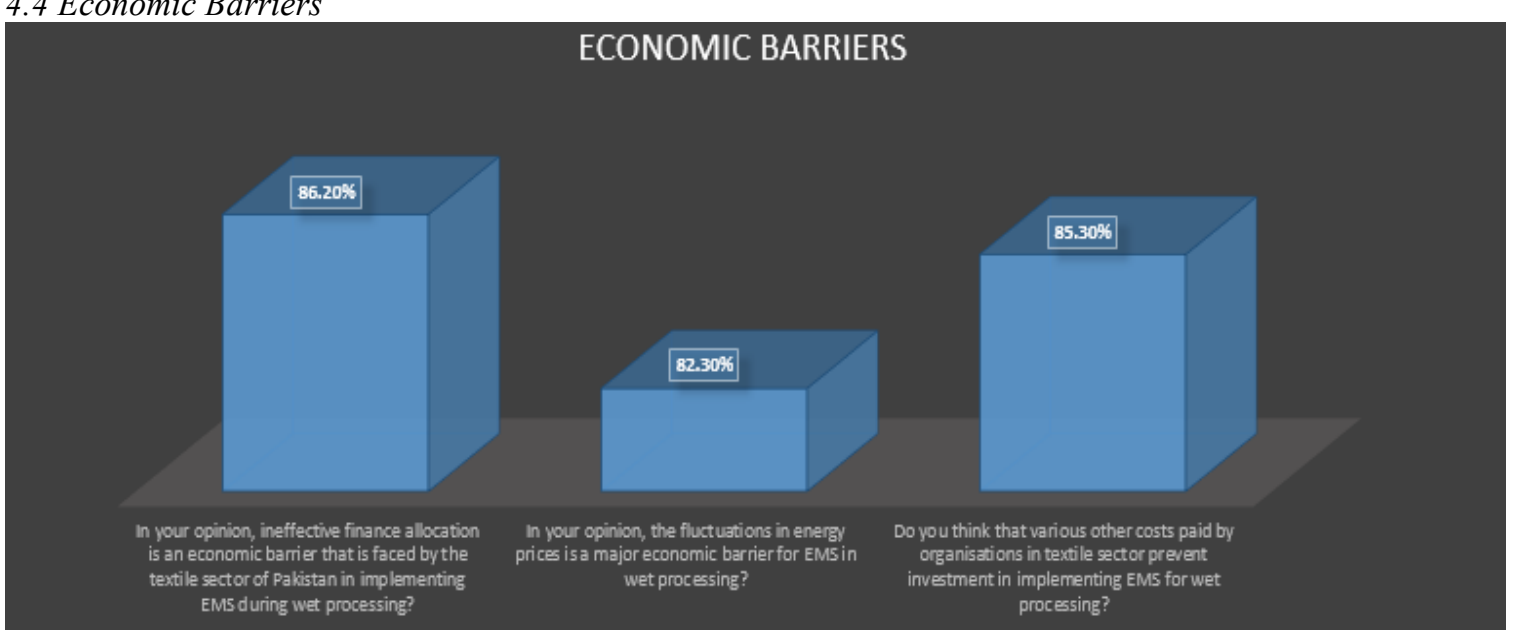

The section gets into significant depth related to the narrowed focus of the barriers to the economy and those that translated into economic barriers. The first and foremost of which are the finances allocated to implement energy management systems. A vast majority believe that truly, lack of apt finance allocation resulted in EMS being delayed in the textile sector of the country. With $86.20 \%$ of the respondents in agreement with the statement and share the same opinion that finances not being allocated by organizations in the textile industry limited the scope of venturing for EMS implementation. Similar was the case with the energy prices in Pakistan, this was agreed by $82.30 \%$ of the people. Of the many economic barriers energy prices fluctuating can be the leading one. This was the very barrier that resulted in an inapt allocation of finances. Tariffs in Pakistan are not stagnant or idle they keep on changing; thus, they limit the ability of the textile industry organization to plan EMS for their wet processing. This would potentially limit the all over effectiveness that the textile sector of Pakistan can have in using EMS for optimal energy consumption. The survey found that other costs, which would be the cost of operations in the form of taxation, were another economic barrier that the textile sector had to face for wider implementation of EMS in their operations. $85.30 \%$ can be considered a significant proportion of total sample which was in agreement that if these extras costs were to some extent reduced the textile sector could have a chance to effective energy management systems being used. If [one is to consider the interviews conducted, two managers had an identical response to the fact that they in the textile industry faced costs of operations such as energy pricing and bills they had to pay.

The response was by Manager $A$ and $C$ :

"I believe we at the textile sector face huge bills only for the wet processing duration if it was to be divided between the various processes of textile production. And yes economic barriers are the biggest of them all. At one point we could train our employees for the EMS, but no security of the same utility prices and also additional taxes limit the financial ability we have." 


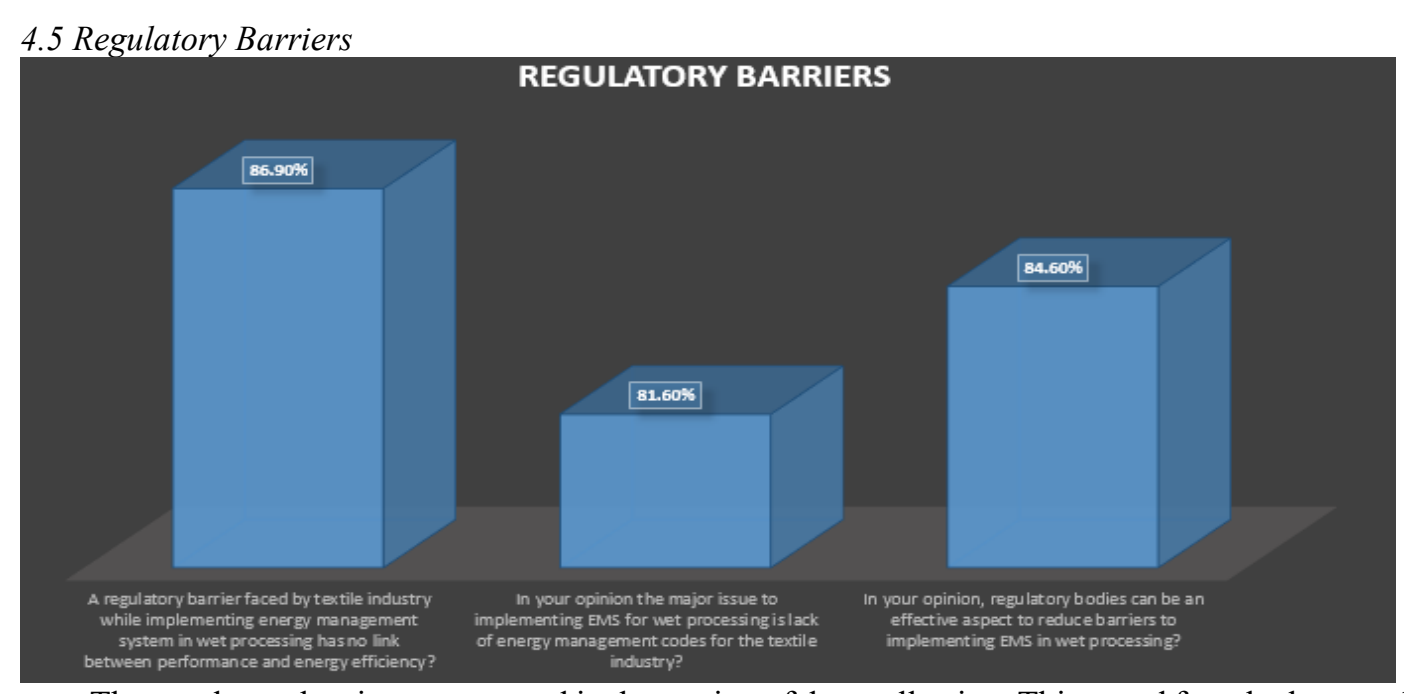

The regulatory barriers were tested in the section of data collection. This tested for whether regulatory barriers were faced or not by the textile sector when they took initiatives for energy management systems. It was an important aspect which was agreed by many of the respondents $(86.90 \%$ to be exact) that the Pakistani policies for the textile sector or any industry do not link the productivity and the energy consumption together. A better chance of implementing energy management systems could be achieved had the Government deployed nay performance measures that would link energy efficiency with the level of productivity achieved. This is where the textile sector consumes immense energy and productivity remains the same. It can be considered form the very next statement to which $81.60 \%$ had agreed that an office Energy Code could be the regulation set by the Pakistani government to have textile sector organization bent on energy management system implementation. But this emerged as another regulatory barrier with the government found to lack any such Energy code. An energy regulatory body for the textile sector, especially to the wet processing or in general, is missing. This serves the fact the use of the greater and more structured strategies to introducing energy management system are omitted by the textile sector organization. This may be the case as they do not find a check and balance or particular regulation limiting their energy consumption during a single operation such the wet processing.

\section{Conclusions}

The above research has highlighted the fact that wet processing in the textile sector is truly an energy-intensive process that requires huge amounts of not electrical but other energy such as heat as well. This has been deduced based on multiple processes such as the bleaching; dyeing and etc. are the part of it. It thus serves its position as one of the most power-intensive operations within the textile industry. Pakistan falls short on its energy needs and the ability to provide energy. Its deficit remains largely due to non-efficient energy management, and more clearly as a result of the research, it has been found that energy management systems are a relatively unique concept within the industry. The textile sector, while it contributes largely to the growth of the economy of Pakistan, has to witness a number of issues that relate to economic and regulatory areas of the country. In light of the above research, it can be effectively concluded that one of the major barriers observed in the implementation of energy management system within the wet processing in the Textile Sector of Pakistan is the rise in electricity and other utility tariffs. They form the economic barriers for the textile sector, which would have easily ventured into investing for the energy management systems. Reduced profitability becomes a pressing issue as the textile sector stays deep into cost management. It has lesser finances saved to invest in the energy management system for its intense energy usage during wet processing. This stands as the biggest economic issue which needs to be resolved. However, it may be listed on the potential economic issues that are resisting the textile sector in Pakistan from extending its research and implementation of energy management systems in the wet processing area of the textile industry of Pakistan. The research remained bent over the economic and regulatory barriers only due to the fact that operational barriers had previously been studied. In the case of the regulatory barriers, it can be concluded that monitoring such a large industry remains the role of a government. In Pakistan, despite the energy sector going in a deficit of supply, the government has not yet been able to regulate energy efficiency in the power-intensive sector like the textile sector. A wide number of issues form the regulatory barriers. An Energy Code which would help the government link sector-wise performance with energy that it consumes is considered important. Yet in its absence, energy consumption during wet processing and other similar processes remains far more intensive than originally required. Efficient energy management systems while they can be a potential chance for the textile sector to have control over energy consumption during wet processing. Pakistan as a country already faces a deficit in energy which grows in severity as the power-intensive sectors fail to deploy energy management systems. 


\section{References}

Alkaya, E. \& Demirer, G.N. (2014). Sustainable textile production: a case study from a woven fabric manufacturing mill in Turkey. Journal of Cleaner Production, 65, 595-603.

Alvesson, M., \& Sköldberg, K. (2017). Reflexive methodology: New vistas for qualitative research. Sage.

Backlund, S., Thollander, P., Palm, J. \& Ottosson, M. (2012). Extending the energy efficiency gap. Energy Policy, 51, 392-396.

Brunke, J.C., Johansson, M. \& Thollander, P. (2014). An empirical investigation of barriers and drivers to the adoption of energy conservation measures, energy management practices and energy services in the Swedish iron and steel industry. Journal of Cleaner Production, 84, 509-525.

Bunse, K., Vodicka, M., Schönsleben, P., Brülhart, M. \& Ernst, F.O., 2011. Integrating energy efficiency performance in production management-gap analysis between industrial needs and scientific literature. Journal of Cleaner Production, 19(6-7), pp.667-679.

Daily Times (2019). UNIDO launches programme on EnMS for industries. Retrieved from < https://dailytimes.com.pk/436398/unido-launches-programme-on-enms-for-industries/ >

Dawn (2012). Poor governance deepens the energy crisis. Retrieved from $<$ https://www.dawn.com/news/710729 $>$

Diabat, A., Kannan, D., \& Mathiyazhagan, K. (2014). Analysis of enablers for implementation of sustainable supply chain management-A textile case. Journal of cleaner production, 83, 391-403.

Hassan, M.T., Burek, S. \& Asif, M., 2017. Barriers to industrial energy efficiency improvement-manufacturing SMEs of Pakistan. Energy Procedia, 113, pp.135-142.

Hepbasli, A., \& Ozalp, N. (2003). Development of energy efficiency and management implementation in the Turkish industrial sector. Energy Conversion and Management, 44(2), 231-249.

Johansson, M.T. (2015). Improved energy efficiency within the Swedish steel industry - the importance of energy management and networking. Energy Efficiency, 8(4), 713-744.

Khan, A.A. \& Khan, M. (2010). Pakistan textile industry facing new challenges. Research journal of international studies, 14(14).21-29.

Khude, P. (2017). A review of energy management in the textile industry. Innov Ener Res, 6(169), 2.

May, G., Stahl, B., Taisch, M., \& Kiritsis, D. (2017). Energy management in manufacturing: From a literature review to a conceptual framework. Journal of Cleaner Production, 167, 1464-1489.

Mirjat, N.H., Uqaili, M.A., Harijan, K., Valasai, G.D., Shaikh, F. \& Waris, M. (2017). A review of energy and power planning and policies of Pakistan. Renewable and Sustainable Energy Reviews, 79, 110-127.

Mori, M., Fujishima, M., Inamasu, Y. \& Oda, Y., (2011). A study on energy efficiency improvement for machine tools. CIRP Annals, 60(1), 145-148.

Nadeem, F. (2014). Barriers, Drivers and Policy Options for Improving Industrial Energy Efficiency In Pakistan. Int. J. Eng., (8), 49-59.

Pakistan Foundry Association (2019). Overview of EnMS Implementation in Foundry Sector of Pakistan. Retrieved from < http://pfa.org.pk/pdf/GIZ\%20Report.pdf $>$

Shaikh, M. A. (2009). Environmental issues related to the textile sector. Pakistan Textile Journal, 10, 36-40.

Silverman, D. (Ed.). (2016). Qualitative research. Sage.

Stacks, D. W., \& Salwen, M. B. (Eds.). (2014). An integrated approach to communication theory and research. Routledge.

Thollander, P., \& Palm, J. (2012). Improving energy efficiency in industrial energy systems: An interdisciplinary perspective on barriers, energy audits, energy management, policies, and programs. Springer Science \& Business Media.

Uddin, F. (2014). Energy management and energy crisis in textile finishing. American Journal of Energy Research, 2(3), 53-59.

United Nations Industrial Development Organization (2019). Development and Promotion of Sustainable, Innovative and Cleaner Technologies in Pakistan. Retrieved from $<$ http://www.unidogefpakistan.org.pk/energy-management-system > 


\section{Appendix}

7.1 Questionnaire

\begin{tabular}{|c|c|c|c|c|}
\hline \multicolumn{5}{|l|}{ Questionnaire } \\
\hline \multicolumn{5}{|l|}{ Demographic } \\
\hline \multicolumn{5}{|l|}{ Year of experience } \\
\hline Less than one year & $1-3$ years & 3-5 years & \multicolumn{2}{|c|}{ More than five years } \\
\hline \multicolumn{5}{|l|}{ Department } \\
\hline $\begin{array}{l}\text { Production } \\
\text { department }\end{array}$ & Finance department & $\begin{array}{l}\text { Operational } \\
\text { department }\end{array}$ & \multicolumn{2}{|c|}{ Engineering department } \\
\hline \multicolumn{5}{|l|}{ Statements } \\
\hline \multicolumn{5}{|c|}{ Energy management systems are widely applied during wet processing in the textile sector of Pakistan. } \\
\hline Strongly agree & Agree & Neutral & Disagree & Strongly disagree \\
\hline \multicolumn{5}{|c|}{$\begin{array}{l}\text { Do the barriers in implementing energy management systems reduce the overall productivity of the textile } \\
\text { industry? }\end{array}$} \\
\hline Strongly agree & Agree & Neutral & Disagree & Strongly disagree \\
\hline \multicolumn{5}{|c|}{$\begin{array}{l}\text { In your opinion, the management should consider implementing energy management systems to enhance } \\
\text { operations? }\end{array}$} \\
\hline Strongly agree & Agree & Neutral & Disagree & Strongly disagree \\
\hline \multicolumn{5}{|c|}{$\begin{array}{l}\text { In your opinion, excessive energy consumption is one of the major issue that is faced by the textile industry due } \\
\text { to lack of proper energy management }\end{array}$} \\
\hline Strongly agree & Agree & Neutral & Disagree & Strongly disagree \\
\hline \multicolumn{5}{|l|}{ Economic Barriers } \\
\hline \multicolumn{5}{|c|}{$\begin{array}{l}\text { In your opinion, ineffective finance allocation is an economic barrier that is faced by the textile sector of } \\
\text { Pakistan in implementing EMS during wet processing? }\end{array}$} \\
\hline Strongly agree & Agree & Neutral & Disagree & Strongly disagree \\
\hline \multicolumn{5}{|c|}{ In your opinion, the fluctuations in energy prices are a major economic barrier for EMS in wet processing? } \\
\hline Strongly agree & Agree & Neutral & Disagree & Strongly disagree \\
\hline \multicolumn{5}{|c|}{$\begin{array}{l}\text { Do you think that various other costs paid by organizations in the textile sector prevent investment in } \\
\text { implementing EMS for wet processing? }\end{array}$} \\
\hline Strongly agree & Agree & Neutral & Disagree & Strongly disagree \\
\hline \multicolumn{5}{|l|}{ Regulatory Barriers } \\
\hline \multicolumn{5}{|c|}{$\begin{array}{l}\text { A regulatory barrier faced by textile industry while implementing energy management system in wet processing } \\
\text { has no link between performance and energy efficiency? }\end{array}$} \\
\hline Strongly agree & Agree & Neutral & Disagree & Strongly disagree \\
\hline \multicolumn{5}{|c|}{$\begin{array}{l}\text { In your opinion the major issue to implementing EMS for wet processing is lack of energy management codes } \\
\text { for the textile industry? }\end{array}$} \\
\hline Strongly agree & Agree & Neutral & Disagree & Strongly disagree \\
\hline \multicolumn{5}{|c|}{$\begin{array}{l}\text { In your opinion, regulatory bodies can be an effective aspect to reduce barriers to implementing EMS in we } \\
\text { processing? }\end{array}$} \\
\hline Strongly agree & Agree & Neutral & Disagree & Strongly disagree \\
\hline
\end{tabular}

\subsection{Interview Questions}

1. Why do you think energy efficiency is important for the textile industry?

2. Do you believe economic barriers limit energy management system implementation in wet processing of Pakistan textile industry? What according to you is the biggest economic barrier to it?

3. What do you think is the biggest regulatory barrier for the energy management system? Is lack of energy code to measure wet processing efficiency a regulatory barrier?

4. With energy management systems important for wet processing in the textile sector, do you think increasing energy tariffs limit the implementation of EMS?

5. In your opinion, do you believe regulations and policies to implement energy management system at government level will reduce regulatory barriers? 